\section{T'ang Pottery for the British Museum}

A REMARKABLE example of T'ang pottery, well known to collectors and students, from the collection of the late Mr. George Eumorfopoulos, has been given to the British Museum by his widow to mark his long and close friendship for that institution, of which he was a generous benefactor. The gift is a pottery model of a saddled horse. It stands just under a foot high, and is an outstanding example of the technical skill and artistic feeling of the Chinese under the T'ang dynasty. This period (A.D. 618-905) was one of the most remarkable in the history of the Chinese Empire. A consolidation and expansion of the imperial power after a time of stress, combined with a revival in the spirit of Buddhism, inspired from its sources in India by the pilgrimages of Chinese priests, to give birth to a remarkable achievement in all forms of the plastic arts, but more notably as exemplified in pottery figures from tomb burials and in the paintings such as those collected in large numbers by Sir Aurel Stein and those who, after him, visited the Buddhist cave shrines of Tun-Huang. The piece of pottery which has now been given to the British Museum was for long highly prized by its former owner and was his favourite specimen. It is known as the 'Blue Horse' on account of the extensive splashing of blue on its glaze, which makes it unique among figures from the tomb burials which are the main source of our knowledge of this type of art in the period.

\section{Racial Characters in Ancient India}

Examrnation of a skull from Chanhu-Daro, a site of the Indus Valley civilization in northern India, by Dr. Wilton M. Krogman, of the University of Chicago, it is stated in a communication circulated by Science Service of Washington, has demonstrated a combination of characters more usually to be assigned to diverse racial types. The skull in question is that of a young female and had been placed in a jar after decapitation. It is thought that it may have been that of a princess or priestess. It was found in the course of the excavations now being carried out by an expedition of the Boston Museum of Fine Arts, and has been dated as belonging to a period some five thousand years ago. Dr. Krogman's report indicates a combination of such negroid characters as a flattened head vault, broad nose opening and low eye-sockets with Caucasoid features such as narrow nasal bones, small teeth, and narrow distance between the eyes, as well as in the shape of the palate. His conclusion is that it represents "a proto-Mediterranean type in which ancestral negro traits have manifested themselves" and he goes on to suggest that the modern Mediterranean race may once have had a mixture of negroid blood which has since been eradicated.

\section{Children under Foster Care}

The July number of the Journal of Psychology contains an interesting study of children under foster care by James W. Layman, of the Mental Health Service, Des Moines, Iowa, based on the examination of eighty-three children. Each of the homes to which the children were admitted was investigated with reference to its environment, physical condition, family history of both boarding parents, financial security of the home, family home life, interests and recreation. The original problems presented by the children included high frequency of lying, truancy, petty stealing, enuresis, timidity, aggressiveness, school maladjusiment, larceny of motors, and housebreaking. The age of the children at the time of admission to the homes ranged from six to sixteen years. The outlook was most favourable in the case of the younger children, while the least favourable prognosis was presented by the older children in whom family backgrounds showed a high degree of instability.

\section{Vital Statistics of the United States}

THE summary of vital statistics of the United States for 1938, recently published (Public Health Rep., 55, 933 ; 1940), gives the following information. There were 2,286,962 births and 1,381,391 deaths, giving a birth-rate of $17 \cdot 6$ and a death-rate of $10 \cdot 6$ per 1,000 population. Of the total deaths 116,702 were of infants less than one year of age, giving an infantile mortality of 51.0 per 1,000 live births. There were 25,644 sets of twins, 262 sets of triplets and 1 set of quadruplets as compared with 24,881, 219 and 4 respectively in 1937. There was a net natural increase of $7 \cdot 0$ per 1,000 population, the largest since 1930. The infantile mortality rate has shown an interrupted decline from 68.7 in 1928 to $51 \cdot 0$ in 1938 , while the maternal mortality rate has fallen continuously during the eleven-year period from 6.9 to $4 \cdot 4$. As regards the causes of death in infancy, premature births stand highest in the list, while pneumonia, diarrhœa and enteritis and congenital malformations come next in the order stated. The cancer death-rate in the United States has $r$ sen from $104 \cdot 1$ in 1934 and $112 \cdot 0$ in 1937 to 114.6 in 1938. The deaths from motor accidents in the United States in $1938(23 \cdot 5$ per 100,000 population) was the lowest since $1923(23 \cdot 3)$. In 1937 the rate was $28 \cdot 8$.

\section{Isis and Osiris}

The publication of Isis, an international and polyglot quarterly devoted to the history and philosophy of science, was begun in Belgium in 1912-13. Five issues had appeared when the publication was stopped by the German invasion. After the War, publication was continued, the journal being edited in the United States, but printed in Brussels, later in Bruges. In 1921, the History of Science Society was founded in Boston, Mass., in order to guarantee and promote the publication of Isis. During the past sixteen years, no less than twenty-five volumes of the journal have been published. With the invasion of Belgium this year, publication was again interrupted. The editor, Dr. George Sarton, Mass., informs us that No. 84 (completing vol. 31) of Isis and No. 85 (vol. 32) were ready for press, and it is hoped to issue at least No. 84 this year. Inquiries should be sent to the secretarytreasurer of the History of Science Society, Dr. H. R. Viets, 8 The Fenway, Boston, Mass. From 1941 on 